\title{
Violência intrafamiliar contra crianças e adolescentes na percepção de mães agressoras
}

Intrafamily violence against children and adolescents from the perspective of aggressive mothers

Violencia intrafamiliar contra niños y adolescentes en la percepción de madres agresoras

Daniela Borges Bittar¹, Ana Márcia Spanó Nakano², Marta Angélica lossi Silva³,

Eliana Mendes de Souza Teixeira Roque ${ }^{4}$

\section{RESUMO}

A violência intrafamiliar afeta todos os membros da família, porém, crianças/adolescentes são as principais vítimas. Este estudo objetivou compreender os significados atribuídos por mães usuárias de drogas sobre a violência perpetrada junto a seus filhos, tendo por base seu contexto histórico-social. Utilizou-se uma abordagem qualitativa e para a coleta de dados foram realizadas entrevistas abertas com dez mulheres. A análise temática de conteúdo foi adotada, constatando-se que o contexto familiar e sociocultural em que viveram as mulheres, durante seu processo de socialização na família de origem, reunia fatores contribuintes para dissociações importantes no desempenho dos papéis maternos, destacando-se: perdas de entes queridos, situações de afetos/desafetos, alcoolismo, pobreza e violência, que não se modificaram em suas famílias atuais. Enfatiza-se a essencialidade da família no trabalho de proteção integral a crianças/adolescentes; além de um trabalho junto aos agressores, que também requerem cuidados, a fim de minimizar e combater este tipo de violência.

Descritores: Violência; Relações Familiares; Criança; Adolescente; Enfermagem em Saúde Pública.

\section{ABSTRACT}

Intrafamily violence affects all family members; however, children/adolescents are the primary victims. This study aimed at understanding the meanings attributed by mothers who use drugs regarding the violence perpetrated against their children, based on their social-historical context. The study utilized a qualitative approach and data were collected through open interviews with ten women. Content thematic analysis was adopted, revealing that the family and sociocultural context in which these women lived during their process of socialization in their original family contributed to important dissociations in the development of maternal roles, particularly: loss of close relatives, situations of affection/disaffection, alcoholism, poverty and violence, situations which remained unchanged in their current families. It is important to emphasize the necessity of the family in the integral protection of children/adolescents, as well as in taking action against the aggressors, who also require care, in order to minimize and target this type of violence.

Descriptors: Violence; Family Relations; Child; Adolescent; Public Health Nursing.

\section{RESUMEN}

La violencia familiar afecta integralmente a la familia; sin embargo, niños y adolescentes son las principales víctimas. Se objetivó comprender los significados atribuidos por madres adictas a drogas sobre la violencia perpetrada contra sus hijos, en base al contexto histórico-social. Se utilizó abordaje cualitativo, datos recolectados en entrevistas abiertas con diez mujeres. Se adoptó el análisis de contenido temático, constatándose que el contexto familiar y sociocultural en que vivieron las mujeres durante su proceso de socialización en la familia de origen reunía factores favorecedores de disociaciones importantes en el desempeño de los papeles maternos, destacándose: pérdida de seres queridos, situaciones de afectos/desafectos, alcoholismo, pobreza y violencia, que no se modificaron en sus familias actuales. Se enfatiza la esencialidad de la familia en el trabajo de protección integral a niños/adolescentes; además de un trabajo conjunto con los agresores, que también requieren cuidados, apuntando a minimizar y combatir este tipo de violencia.

Descriptores: Violencia; Relaciones Familiares; Niño; Adolescente; Enfermería en Salud Pública.

\footnotetext{
${ }^{1}$ Enfermeira, Mestre em Enfermagem. Ribeirão Preto, SP, Brasil. E-mail: danielabbittar@yahoo.com.br.

2 Enfermeira, Doutora em Enfermagem. Professora Titular da Escola de Enfermagem de Ribeirão Preto da Universidade de São Paulo (EERP/USP). Ribeirão Preto, SP, Brasil. E-mail: nakano@eerp.usp.br.

${ }^{3}$ Enfermeira, Doutora em Enfermagem. Professora Doutora da EERP/USP. Ribeirão Preto, SP, Brasil. E-mail: maiossi@eerp.usp.br.

${ }^{4}$ Assistente Social, Doutora em Saúde Pública. Professora Doutora da Universidade de Ribeirão Preto. Ribeirão Preto, SP, Brasil. E-mail: jkroque@uol.com.br.
} 


\section{INTRODUÇÃO}

A violência, em suas diferentes manifestações, seja interpessoal, comunitária ou estrutural, é na atualidade um tema recorrente em diferentes contextos sociais e a violência intrafamiliar, especificamente, também não é uma ocorrência exclusiva de determinada classe, faixa etária ou população, entretanto certos grupos da sociedade, como mulheres, crianças/adolescentes e idosos são prioritariamente vitimizados ${ }^{(1)}$.

A violência contra crianças e adolescentes ocorre em todas as partes do mundo, em todas as culturas e extratos sociais e em diferentes épocas da história da humanidade. Em razão de esses indivíduos serem desprovidos de defesa e permanecerem por longo tempo na dependência de outrem, são vítimas constantes dos diversos tipos de violência, impetrados, na grande maioria das vezes, por pessoas de convívio muito próximo, justamente responsáveis em cuidar-lhes e garantir-lhes segurança e desenvolvimento saudável(23).

Ademais, a exposição frequente à violência na infância e adolescência pode levar a uma adaptação social negativa, causando internalização de problemas como ansiedade, depressão e baixa autoestima ${ }^{(4)}$; além desses traumas na infância estarem intimamente relacionados a desajustes psicológicos tardios e a conflitos em relacionamentos na idade adulta ${ }^{(5)}$.

Pesquisas nacionais e internacionais apontam a importância da violência intrafamiliar ${ }^{(6-8)}$, apesar de seus dados apresentarem-se subestimados em todo o mundo devido a invisibilidade que permeia a violência. No que diz respeito aos agressores, estudos científicos constataram $^{(9-10)}$ que a mãe foi o agressor que contribuiu com a maior prevalência para a violência contra os filhos, caracterizada, principalmente, pela negligência.

A respeito dessa violência praticada pelas mães, considera-se que as agressões físicas e as de ordem psicológica são remanescentes de uma cultura que compreende os castigos ou punições corporais e a desqualificação moral ou a humilhação da pessoa como recursos de socialização e práticas educativas ${ }^{(7)}$. Assim, autores concordam que a violência intrafamiliar é frequentemente justificada pelos agressores como forma de educar e corrigir transgressões de comportamento ${ }^{(7,11)}$. Ainda permanecem algumas questões, como as que se referem aos limites entre o que é e o que não é violência, relacionadas aos valores culturais de educação das crianças, vistas como seres em formação que seriam propriedade de seus pais, e que, para educá-las, haveria necessidade de puni-las quando erram ou se insubordinam ${ }^{(11)}$.

O espaço de interação entre mães e filhos em seu contexto de vida, pode ser capaz de revelar as multiplicidades de fatores que favorecem a expressão da violência, como por exemplo: pobreza, relações conflitantes do casal, uso de drogas lícitas e ilícitas, vivência de violência conjugal na infância ou ter sofrido abuso quando criança, longo tempo de permanência entre mães e filhos, dentre outros. A este respeito, considera-se que a tendência atual dos pesquisadores é de considerar a interação de diferentes fatores pessoais, situacionais e socioculturais combinando-se para provocar o abuso(12).

A dependência de substâncias psicoativas pelas mulheres/mães ou outros membros da família também se constitui como um dos fatores que favorecem a expressão da violência, por meio de atitudes agressivas e negligentes com os filhos ${ }^{(13)}$; realidade esta que temos nos deparado atuando em um Projeto de Extensão Universitária denominado "Intervenções Breves para pessoas que abusam de álcool e drogas" junto a famílias de crianças e adolescentes vítimas de violência, cujas mulheres/mães constituem o universo empírico desta pesquisa.

No espaço de atuação do projeto supracitado foi aberta a possibilidade de aproximação com famílias que se encontravam sob intervenção judicial por violência intrafamiliar contra crianças e adolescentes. Dentro desse contexto - considerando a importância e complexidade do fenômeno da violência contra crianças e adolescentes - a presente investigação teve por objetivo compreender os significados atribuídos por mães usuárias de drogas lícitas e ilícitas sobre a violência perpetrada junto a seus filhos. Fazemos uma reflexão a respeito das ambiguidades de mulheres/mães enquanto cuidadoras e agressoras de seus filhos, tendo por base seu contexto histórico-social.

Sendo a violência um fenômeno multideterminado, de ampla magnitude, justifica-se a relevância deste estudo, pois a compreensão dos determinantes e significados da violência intrafamiliar caracteriza-se como um importante passo, na saúde pública, para a prevenção e atenção ao fenômeno. Entendemos que compreender a questão nos possibilita encontrar 
caminhos que vão além de medidas protetivas; como comumente se faz nos casos da violência infantil, mantendo crianças em abrigos, afastando-as do ambiente agressor por um período de tempo e reintroduzindo-as naquele mesmo ambiente de conflito.

A família é reconhecidamente fundamental no trabalho de proteção integral a crianças e adolescentes. Quando há necessidade de afastamento da família, os esforços devem acontecer para que a reintegração se dê no menor tempo possível e, especialmente, para que as referências familiares não sejam perdidas. Cabe aos profissionais de diversas áreas, especialmente da saúde, não apenas dar suporte aos pais, mas mostrar a importância de responderem construtivamente diante de uma situação de violência; como também ajudá-los a desenvolver habilidades relacionais, parentais e sociais para enfrentar situações vulnerabilizantes e conflituosas, evitando atos violentos.

\section{MÉTODOS}

Рara a compreensão do objeto de estudo, optou-se pela abordagem qualitativa, sendo o universo empírico considerado de mulheres, participantes do Projeto "Intervenções Breves para pessoas que abusam de álcool e drogas", instituído em Jardinópolis/SP, junto à Fundação PROMAR (Projeto Marcenaria da Música de Jardinópolis), tendo a pesquisadora principal participado do projeto ativamente durante 18 meses.

Esse projeto foi criado após constatação, em estudos científicos ${ }^{(14-15)}$, de que os casos de violência intrafamiliar que chegavam ao Poder Judiciário na Comarca de Jardinópolis, mesmo pós-intervenção judicial, continuavam reincidentes, sendo que o município não dispunha de um núcleo de atenção aos usuários de drogas.

O recorte empírico do estudo deu-se por saturação(16) e foi composto por 10 mulheres, mães, maiores de 18 anos, usuárias de drogas lícitas e ilícitas, integrantes do grupo de apoio supracitado e que aceitaram participar da pesquisa, assinando o Termo de Consentimento Livre e Esclarecido.

Dentre as técnicas para coleta de dados, utilizou-se a História de Vida Tópica(17), uma entrevista aberta, que busca a visão da pessoa acerca de suas experiências subjetivas de certas situações, as quais estão inseridas em um período de tempo de interesse ou se referem a algum evento ou série de eventos que possam ter tido algum efeito sobre o respondente. Neste estudo, estão relacionadas ao processo de socialização das mulheres entrevistadas e ao seu relacionamento mãe-filho.

As entrevistas foram aplicadas pela pesquisadora principal, no período de fevereiro a junho de 2009, por meio de um roteiro norteador e gravadas; possuindo duração média de uma hora, cada uma. Nesse roteiro, construído pelas pesquisadoras, são abordadas cinco etapas de forma dinâmica e aberta, não estática, sendo elas: dados de identificação, como idade, renda, ocupação, número de filhos, escolaridade, número de membros da família que moram juntos e desempregados; dados sobre a família de origem da entrevistada; dados sobre seus relacionamentos, parceiros anteriores e atual, pontos positivos e negativos; relacionamento com seus filhos, suas concepções sobre educação, maternidade, atitudes perante erros e acertos dos filhos e se os filhos foram planejados; além de situações de violência intrafamiliar.

A pesquisa foi conduzida dentro dos padrões exigidos pela Declaração de Helsinque respeitando-se os aspectos éticos para desenvolvimento de pesquisas com seres humanos, atendendo à Resolução 196/96. A coleta de dados foi realizada após a aprovação do Comitê de Ética em Pesquisa da Escola de Enfermagem de Ribeirão Preto da Universidade de São Paulo, protocolo de aprovação nº. 0946/2008. A participação das mulheres se deu de forma voluntária, após a leitura e assinatura do Termo de Consentimento Livre e Esclarecido, incluindo a permissão para a gravação da entrevista. Com o objetivo de garantir o anonimato, foram utilizados códigos de identificação nos fragmentos das entrevistas.

Utilizamos, para o tratamento dos dados, a técnica de análise de conteúdo, modalidade temática, a qual perpassa pelas etapas de pré-análise, exploração do material, tratamento dos resultados obtidos e interpretação(18).

\section{RESULTADOS E DISCUSSÃO}

O universo empírico do estudo, composto por 10 mulheres, apresentou uma média de idade de 35 anos, variando de 22 a 47 anos. Quanto à ocupação, $80 \%$ eram do lar, a grande maioria das mulheres não possuía atividade remunerada. Cerca de $70 \%$ das entrevistadas, cursaram apenas ensino fundamental incompleto e $20 \%$ eram analfabetas, o que significa que $90 \%$ das mulheres possuíam baixa ou nenhuma escolaridade. Sobre o 
estado civil, 50\% possuíam relação estável, havendo um grande número de famílias reconstituídas ou recompostas. A renda familiar variou de zero a $\mathrm{R} \$ 500,00$, mas $90 \%$ dos sujeitos referiram viver com menos de um salário mínimo.

Quando se analisou o número de filhos, foi verificada uma média de cinco filhos vivos por mulher, havendo uma variação de um a onze filhos. É relevante colocar que apenas uma mulher possuía um único filho, sendo que estava grávida no momento da entrevista e relatou ter abortado cinco ou seis vezes devido à violência física cometida pelo parceiro.

Em análise às falas sobre as trajetórias de vida na família de origem e sobre a relação intrafamiliar atual das mulheres participantes do estudo, depreendemos as categorias temáticas abaixo relacionadas, as quais foram divididas em dois momentos: trajetórias de vida na família de origem e na família atual.

\section{Trajetórias de vida na família de origem}

\section{Convivendo com as perdas: "... eu fiquei pro mundo"}

Um fato marcante observado nas falas das entrevistadas foi a grande frequência de perdas precoces de familiares próximos na infância, como a mãe ou o pai, o que se apresentava como vivências comuns às mulheres, acarretando desestruturação da família nuclear - aquela formada por pai, mãe e filhos.

Morava com minha madrinha, meu pai morreu com 30 anos. Minha mãe é viva... Eu vim pra cá porque minha mãe não tinha condição de criar nós, quatro irmãos, aí ela deu nós pra minha madrinha (S2).

Quando a minha mãe era viva eu morava com ela. Quando ela morreu eu tinha 8 ano. Morreu meu pai e minha mãe. Aí eu fiquei pro mundo (S10).

Identifica-se nas famílias de origem das mulheres entrevistadas um dado importante, a perda de entes queridos, o que possui significado relevante no campo afetivo das relações na família. Quando a criança é privada de uma relação de afeto contínua com a mãe ou mãe substituta, de acordo com o grau de privação, podem ser gerados fortes sentimentos de vingança, angústia, exagerada necessidade de amor e, consequentemente, culpa e depressão(19). Como a criança pequena não sabe lidar com essas emoções, sua forma de reação a tais perturbações pode resultar em distúrbios nervosos ou em uma personalidade instável, por exemplo. As mulheres, como mães, são agentes decisivos na esfera da reprodução social, pois são as que mais participam da educação, transmitindo aos filhos as ideologias vigentes na sociedade(20). Identificamos que muitas dessas mulheres não tiveram uma referência materna estruturada e permanente.

A perda do pai também é bastante difícil, já que os homens são reconhecidamente importantes à sobrevivência econômica da família(20).

\section{Convivendo com afetos e desafetos}

Situações de desafeto, e raras de afeto, se mostram presentes na fala:

eu não tenho muita lembrança boa da minha mãe não, tanto é que, pode ser pecado, mas eu não sinto muita falta dela. Pra dizer a verdade, eu achava tão bom, tão gostoso quando ela me chamava de filha, era muito raro, muito raro... (S4).

Os reflexos em longo prazo podem ser apreendidos nessa fala, em que S4 se lembra da figura materna com certa mágoa; o que se expressa em carência afetiva, negligência nos cuidados e em um relacionamento mãefilha distante.

A vivência de uma relação calorosa, íntima e contínua com a mãe ou mãe substituta mostra-se essencial à saúde mental da criança. É essa relação complexa, rica e compensadora com a mãe, nos primeiros anos de vida, enriquecida de inúmeras maneiras pelas relações com o pai e familiares, que a comunidade científica julga estar na base do desenvolvimento da personalidade e saúde mental(19). Tal condição ideal está longe de ser a realidade que as mulheres entrevistadas conviveram junto a suas mães na infância. 
Convivendo com alcoolismo, pobreza e violência em família

As condições desfavoráveis vivenciadas por estas mulheres em suas famílias de origem durante toda a infância/adolescência incluem a pobreza, o uso abusivo de álcool/drogas, além de violência, deixando evidenciar uma situação de degradação do contexto familiar, exemplificadas pelas falas:

quando meus pais morreram nós tinha uma casa de dois cômodo. A minha prima foi lá e vendeu a nossa casa, aí nós ficou na rua. Fomos morar debaixo de uma mangueira... Nós ia na cidade com latinha e pedia comida e levava tudo pra debaixo da mangueira (S10).

Meu pai bebia, bebia muito, tipo alcoólatra.(...) Quando ele bebia ele ficava agressivo, batia na gente e na minha mãe (S3).

A associação do alto consumo do álcool e práticas de violência tem sido objeto de estudo de autores. O consumo de álcool ou drogas em larga escala no Brasil, principalmente por homens, manifesta-se em mudanças de humor expondo ao maior risco de praticar violência, principalmente contra as mulheres ${ }^{(21)}$.

Além da presença de álcool e drogas na família de origem das participantes do estudo, são enfatizadas em suas falas as situações de violência vividas e presenciadas. Estudos comprovam a associação entre a exposição à violência por parceiro íntimo contra a mulher com desajustes comportamentais dos filhos, o que pode desencadear problemas de comportamento em geral e de comportamentos agressivos ${ }^{(4-5,22)}$.

Independentemente dos fatores desencadeantes e dos casos particulares em que se evidenciam os conflitos intrafamiliares, a violência afeta de uma forma geral a todos da família. Além de presenciar violência conjugal entre seus pais, as mulheres entrevistadas também expõem o quanto sofreram violência, dos mais variados tipos, em sua infância:

ele amarrava nós no fogão pra não escapar, sem blusa. Eu com 12 anos de idade, tava começando a criar peito, uma porque não tinha roupa e outra porque ele tirava nossa roupa pra bater em nós (S7).

Sabe-se que a punição corporal, em longo prazo, pode acarretar prejuízos não somente para o indivíduo que a recebe, mas também para os outros com quem convive, aumentando os índices de delinquência, criminalidade e violência contra o cônjuge ${ }^{(4,22)}$.

A maioria das entrevistadas se lembra da infância como um período ruim devido às agressões física, sexual e psicológica sofridas. Abaixo, um relato de violência sexual:

uma vez ele veio com uma segunda intenção comigo, meio que passando a mão no meu corpo, mas eu já era esperta, falei com minha mãe, mas ela falava que era mentira (S7).

O ambiente familiar é extremamente favorável a todo tipo de violência, especialmente a sexual, por envolver relações de confiança entre a vítima e o abusador, o que favorece que esta violência seja, normalmente, repetitiva e insidiosa. Aponta-se, ainda, que essas vítimas ficam mais propensas à dificuldade de aprendizagem, distúrbios de comportamento, comportamentos autodestrutivos, isolamento social, atitudes erotizadas precoces, baixa autoestima, podendo haver repercussões na família e na sociedade ${ }^{(7-8,22)}$.

\section{Trajetórias de vida na família atual}

\section{Relação conjugal: "Minha vida da infância ao casamento parece que foi igual (...) continuei sendo agredida"}

Nas distintas trajetórias de vida das mulheres entrevistadas encontramos pontos em comum, os quais convergem entre si e podem ser definidos em certo denominador: mulheres que, mesmo provenientes de diferentes famílias, tiveram suas vidas marcadas por sujeição e tentativas de fugir da condição desfavorável em que viviam.

Constatamos que algumas entrevistadas optaram por estabelecer laços conjugais precoces e constituir uma nova família, repetindo o mesmo padrão de família desestruturada, o que pode evidenciar um atravessamento intergeracional pelo processo de socialização, aliado à experiência singular no âmbito das relações familiares.

Eu enrolei minha vida com 13 anos, precisei fugir com o namorado, pra não ser abusada por ele (o padrasto) dentro de casa. O meu namorado eu nem conhecia direito, porque a pessoa pra viver com outra tem que conhecer 
muito, né. Primeiro você tem que saber quem ele é pra depois você casar (S7).

De maus-tratos na infância e adolescência na família de origem, as mulheres passavam a conviver com a violência de gênero que, pelas falas destas mulheres, $100 \%$ estavam em situação de violência:

ele começou a me trair (...), me batia muito. De resguardo da minha filha precisei ir pro hospital porque ele quase me matou, quebrou meu braço na pura pancada (S7).

Dentre os fatores associados à sujeição feminina está o consumo abusivo de drogas lícitas e ilícitas como detonador dos conflitos conjugais, vivenciado pela maioria das mulheres deste estudo.

No início do casamento, há 19 anos, eu sofri muito com ele, porque nós dois bebia, nós brigava e eu saía pior que ele (S1).

A este respeito estudos têm apontado que mulheres vítimas de abuso físico ou sexual associado ao alcoolismo na infância tendem a se casar com homens alcoolistas ${ }^{(23-}$ 24). Tal fato foi observado por esse autor que verificou nos depoimentos das mulheres, sujeitos de seu estudo, a impossibilidade de construir relações mais duradouras com companheiros que não tenham problemas de alcoolismo. A maioria delas teve contato com a bebida muito cedo e conviveu com amigos e amigas também alcoolistas, o que propiciava a relação com uma pessoa que bebesse.

\section{Relação mãe-filho: "Eu bato nele, mas em vista do que fui tratada, trato ele muito bem"}

Historicamente através da maternidade é que as mulheres foram elevadas à condição de ser social. Neste sentido, a identidade e subjetividade femininas tradicionalmente se mostram atreladas à maternidade e ao espaço privado do lar e da família. Tais construções históricas e sociais tendem a ser retomadas quando se atém a visão ideológica de mãe em nossa sociedade, conforme significam as mulheres deste estudo ao falarem sobre o sentido da maternidade para elas:

ser mãe é tudo de bom, tem a parte ruim, mas a parte boa apaga tudo. (...) Chegou uma época que quando eu perdi meus filhos por causa da bebida, eu não podia levar minhas crianças em lugar nenhum... me senti uma bandida.(S4).

Eu ponho eles na escola, dou banho neles, ponho pra dormir; ponho pra assistir desenho... Eu me preocupo com eles em relação à roupa, sapato... (S5).

Identificamos o amor materno nas falas acima e depreendemos que o sentido de cuidar para estas mulheres, em sua essência, se volta a necessidades básicas de prover alimento e vestuário.

Entretanto, ambiguamente, atos de autoritarismo das mães utilizando a punição como medida educativodisciplinar são também referenciados por elas, o que consideram estar muito distante do que foram submetidas quando crianças:

tem que bater... minha mãe não esperava nem chegar em casa, já apanhava no meio da rua (S8).

Minha filha pegou trauma porque já apanhou de coleira de cachorro. Ela tem urina solta, to levando na psicóloga. Eu acho que foi por causa das agressões do pai (S8).

Diferentes pesquisas elaboradas com o objetivo de relacionar o recebimento da punição corporal com alguma variável comportamental da criança encontraram prejuízos para o desenvolvimento infantil: as crianças que apanhavam - comparadas com as que não apanhavam - apresentavam estima mais baixa, comportamento mais agressivo, maior frequência de sintomas psiquiátricos e menor bem-estar geral(22).

Eu bato nele sim, porque eu falo pra ele e ele fingi que não escuta. Mas em vista do que eu fui tratada eu trato ele muito bem (S6).

Socialmente espera-se de uma mãe atos de cuidado, amor e afeto com os filhos, contudo identificamos neste estudo atos de agressão e violência que não são esperados na relação mãe-filho. Fato a ser considerado é que a proximidade da mãe com o filho por longo tempo (lembramos que, quanto à ocupação, 80\% eram do lar), parece favorecer a ocorrência de situações de dificuldades interpessoais, o que é comprovado em um estudo(10) $^{(10}$ identificou ser a mãe a maior agressora dos filhos no ambiente doméstico. Além disso, questiona-se a qualidade dessa relação, a afetividade e as habilidades presentes nessa relação, já que a 
experiência anterior dessas mulheres é marcada por importantes perdas e desafetos.

A falta de habilidades sociais e os traços antissociais dos pais são considerados também importantes fatores de risco familiar. Os traços antissociais maternos são os principais contribuintes para o desenvolvimento de interações coercitivas, as quais, em ambientes familiares, excluem e dificultam a utilização de técnicas positivas de motivação e guia na educação dos filhos ${ }^{(10,25)}$. Enfatizamos novamente que a maioria das mulheres não tiveram uma boa relação mãe-filha ou perderam essa referência cedo demais.

Vale considerar ainda que as marcas deixadas pela violência intrafamiliar na infância são muitas vezes subestimadas, por considerar seu impacto temporário e desaparecer no decorrer do desenvolvimento infantil. Entretanto, a agressão contra a criança/adolescente deve ser reconhecida como um sério problema e, mesmo que esses indivíduos vitimizados sejam retirados de suas casas, os efeitos da experiência vivida repercutirão por toda a sua vida.

Percebemos então que, na família atual das mulheres entrevistadas há uma repetição de seu passado, ocorrendo situações de violência, nas quais elas assumem tanto o papel de vítimas quanto de agressoras. Sendo a violência um problema de múltiplas faces, que tem suas raízes na construção histórica, cultural e social das relações, sua prevenção deve se fundamentar na desconstrução e reconstrução dessas relações perante os indivíduos, as famílias, as comunidades e a sociedade como um todo, para que se possam elaborar e desenvolver estratégias eficazes de prevenção e enfrentamento e tornar possível levar essa compreensão aos espaços sociais, em que a violência é construída e legitimada.

Essa percepção também foi comprovada em outro estudo científico(15) que tinha por objetivo analisar as dimensões estruturais, de desenvolvimento e funcionais de famílias em situação de violência, sob intervenção judicial, no mesmo município desse estudo, que observou famílias que apresentavam vários problemas crônicos, onde o ciclo de multiproblematicidade se renovava no nível geracional, por mecanismo que se pode denominar hereditariedade relacional.

\section{CONCLUSÃO}

A presente investigação teve por objetivo compreender os significados atribuídos por mães usuárias de drogas lícitas e ilícitas sobre a violência perpetrada junto a seus filhos, tendo por base seu contexto histórico e social.

Identificamos claramente através da interpretação das falas das mulheres que, o contexto familiar e social em que viveram durante seu processo de socialização na família de origem, reunia fatores que contribuíam para dissociações importantes no desempenho de seus papéis maternos. Chamamos a atenção para as experiências vivenciada por estas mulheres na infância, ou seja, um passado marcado por desestruturação familiar, em que se somam perdas de entes queridos, situação de pobreza, alcoolismo e uso de drogas na família, além de muita violência.

Assim, o que se pode evidenciar como comum a essas mulheres é um ciclo vicioso de violência. Nas famílias atuais das mulheres, reencenam-se situações de violência, nas quais elas assumem posições que as colocam como agentes dessa violência. Entretanto é importante relativizar o fato de que as mães agridam seus filhos porque foram agredidas na infância. A este respeito, observa-se que os indivíduos que sofreram maus-tratos na infância ou não foram crianças aceitas, reconhecidas ou desejadas, poderão ter consequências que se refletirão no futuro - particularmente na forma como irão tratar seus filhos. Porém, isso não acontece de forma determinista, geralmente há recursos e fatores de proteção que medeiam os efeitos em cada caso.

Frente a esta realidade, entendemos que cabe aos profissionais de saúde dar suporte aos pais, enfatizandose nesta pesquisa a mãe enquanto principal agressora, que também requer ser cuidada, ajudando-a a encontrar caminhos para que recupere sua dignidade e respeitabilidade. Além disso, importante estratégia nessa direção é conhecer a realidade de vida familiar e social das mulheres para dar subsídios ao trabalho de recuperação do vínculo mãe-filho em seu contexto, atuando sobre seus comportamentos ambíguos de afeto versus violência. Esse estudo deu um primeiro passo frente a essa estratégia, mas não esgotamos essa ampla temática, que ainda requer muitas pesquisas com focos diversos.

Acreditamos que refletir sobre o paradigma da proteção integral de crianças e adolescentes ultrapassa, necessariamente, a questão da violência intrafamiliar. É nesta condição de pertencimento a uma família que 
respeite a criança, que a proteja enquanto pessoa humana em fase peculiar de crescimento e desenvolvimento, independentemente de suas características particulares e de suas singularidades, que chamamos a atenção para a necessidade de engajamento sócio-político, a fim de que haja real

\section{REFERÊNCIAS}

1. Dossi AP, Saliba O, Garbin CAS, Garbin AJI. Perfil epidemiológico da violência física intrafamiliar: agressões denunciadas em um município do Estado de São Paulo, Brasil, entre 2001 e 2005. Cad Saude Publica [Internet]. 2008 [cited 2012 dec 31];24(8):1939-52. Available from: http://dx.doi.org/10.1590/S0102$311 \times 2008000800022$.

2. Faria $A L$, Araújo CAA, Baptista VH. Assistência à vítima de violência sexual: a experiência da Universidade de Taubaté. Rev. Eletr. Enf. [Internet]. 2008 [cited 2012 dec 31];10(4):1138-43. Available from:

http://www.fen.ufg.br/revista/v10/n4/v10n4a26.htm.

3. Baptista RS, França ISX, Costa CMP, Brito VRS. Caracterização do abuso sexual em crianças e adolescentes notificado em um Programa Sentinela. Acta paul. enferm. [Internet]. 2008 [cited 2012 dec 31];21(4):602-8. Available from: http://dx.doi.org/10.1590/S0103-21002008000400011.

4. Salzinger S, Rosario M, Feldman RS, Ng-Mak DS. Aggressive behavior in response to violence exposure: is it adaptive for middleschool children? J. Community Psychol. [Internet]. 2008 [cited 2012 dec 31];36(8):1008-25. Available from:

http://dx.doi.org/10.1002/jcop.20275.

5. Browne C, Winkelman C. The effect of childhood trauma on later psychological adjustment. J Interpers Violence [Internet]. 2007 [cited 2012 dec 31];22(6):684-97. Available from:

http://dx.doi.org/10.1177/0886260507300207.

6. Mian M. World Report on Violence and Health: what it means for children and pediatricians. J Pediatr [Internet]. 2004 [cited $2012 \mathrm{dec}$ 31];145(1):14-9. Available from:

http://dx.doi.org/10.1016/j.jpeds.2004.03.054.

7. Iwamoto HH, Oliveira RC, Camargo FC, Tavares LC, Oliveira LP. A violência sexual infanto-juvenil sob a ótica dos informantes-chave. Rev. Eletr. Enf. [Internet]. 2010 [cited 2012 dec 31];12(4):647-54. Available from: http://dx.doi.org/10.5216/ree.v12i4.11699. 8. Lim BH, Adams LA, Lilly MM. Self-worth as a mediator between attachment and posttraumatic stress in interpersonal trauma. J Interpers Violence [Internet]. 2012 [cited 2012 dec 31];27(10):203961. Available from: http://dx.doi.org/10.1177/0886260511431440. 9. Costa MCO, Carvalho RC, Bárbara JFRS, Santos CAST, Gomes WA Sousa HL. O perfil da violência contra crianças e adolescentes, segundo registros de Conselhos Tutelares: vítimas, agressores e manifestações de violência. Cien Saude Colet [Internet]. 2007 [cited 2012 dec 31];12(5):235-241. Available from:

http://dx.doi.org/10.1590/S1413-81232007000500010.

10. Brito AMM, Zanetta DMT, Mendonça RCV, Barison SZP, Andrade VAG. Violência doméstica contra crianças e adolescentes: estudo de um programa de intervenção. Cien Saude Colet [Internet]. 2005 [cited 2012 dec 31];10(1):143-9. Available from: http://dx.doi.org/10.1590/S1413-81232005000100021.

11. Ristum M. A violência doméstica contra crianças e as implicações da escola. Temas em Psicologia [Internet]. 2010 [cited 2012 dec 31];18(1):231-42. Available from:

http://www.sbponline.org.br/revista2/vol18n1/PDF/v18n1a19.pdf. 12. Monteiro EMLM, Brandão Neto W, Gomes IMB, Freitas RBN, Brady CL, Moraes MUB. Violência contra criança e adolescente: rompendo o silêncio. Rev. Rene [Internet]. 2009 [cited 2012 dec 31];10(3):107-16. Available from:

http://www.revistarene.ufc.br/revista/index.php/revista/article/vie w/543/pdf.

13. Hochgraf PB, Brasiliano S. Treatment services for substance abuse that are responsive to gender. A Brazilian experience with entendimento e resolução dessa complexa temática. Conhecer as percepções dessas mulheres quanto à violência cometida, contribui para a identificação de suas necessidades e possibilidades de intervenção para o cuidado em saúde, com ênfase na promoção da saúde.

drug dependent women. In: United Nations Office on Drugs and Crime (UNODC). Substance abuse treatment and care for women: case studies and lessons learned. New York: United Nations Publication. 2004. p. 57-96.

14. Roque EMST, Ferriani MGC. Unveiling violence at home against children and adolescents under the view of law professionals in the municipality of Jardinópolis-SP, Brazil. Rev Lat Am Enfermagem [Internet]. 2002 [cited $2012 \mathrm{dec} 31$ ];10(3):334-44. Available from: http://dx.doi.org/10.1590/S0104-11692002000300008..

15. Roque EMST, Ferriani MGC, Silva MAI. Intrafamily violence and justice. Rev Lat Am Enfermagem [Internet]. 2008 [cited 2012 dec 31];16(5):908-14. Available from: http://dx.doi.org/10.1590/S010411692008000500018.

16. Fontanella BJB, Ricas J, Turato ER. Amostragem por saturação em pesquisas qualitativas em saúde: contribuições teóricas. Cad Saude Publica [Internet]. 2008 [cited 2012 dec 31];24(1):17-7. Available from: http://dx.doi.org/10.1590/S0102311X2008000100003.

17. Bertaux D. L'approche biographique: sa validité méthodologique, ses potentialités in histoires de vie et vie sociale. Cah Int Sociol.1980;27(69):197-225. Français.

18. Minayo MCS. O desafio do conhecimento: pesquisa qualitativa em saúde. 9th ed. São Paulo: Hucitec; 2006.

19. Bowlby J. Cuidados maternos e saúde mental. São Paulo: Martins Fontes, 1988.

20. Chodorow N. Psicanálise da maternidade: uma crítica a Freud a partir da mulher. Rio de Janeiro: Rosa dos Tempos; 1990.

21. Rabello PM; Caldas JAF. Violência contra a mulher, coesão familiar e drogas. Rev Saude Publica [Internet]. 2007 [cited $2012 \mathrm{dec}$ 31];41(6):970-8. Available from: http://dx.doi.org/10.1590/S003489102007000600012.

22. Durand JG, Schraiber LB, França-Junior I, Barros C. Repercussão da exposição à violência por parceiro íntimo no comportamento dos filhos. Rev Saude Publica [Internet]. 2011 [cited $2012 \mathrm{dec}$ 31];45(2):355-64. Available from: http://dx.doi.org/10.1590/S003489102011005000004.

23. Souza J. Filhos de alcoolistas: afetividade e conflito nas relações familiares [thesis]. Ribeirão Preto: Escola de Enfermagem de Ribeirão Preto da Universidade de São Paulo; 2008. 147p.

24. César BAL. Alcoolismo feminino: um estudo de suas peculiaridades. Resultados preliminares. J. bras. psiquiatr. [Internet]. 2006 [cited $2012 \mathrm{dec} 31$ ];55(3):123-130. Available from: http://dx.doi.org/10.1590/S0047-20852006000300006. 25. Patterson GR, Bank L. Some amplifying mechanisms for pathologic processes in families. In: Gunnar MR, Thelen E. (Eds.). Systems and development: the minnesota symposia on child psychology. Hillsdale: Erlbaum Associates; 1989. p. 167-209.

Artigo recebido em 22/09/2011. Aprovado para publicação em 30/06/2012. Artigo publicado em 31/12/2012. 